\title{
Determinants of success and sustainability of the WHO multimodal hand hygiene promotion campaign, Italy, 2007-2008 and 2014
}

ML Moro ${ }^{1}$, F Morsillo ${ }^{1}$, S Nascetti 2 , M Parenti ${ }^{3}$, B Allegranzi ${ }^{4}$, MG Pompa 5 , D Pittet 6

1. Agenzia Sanitaria e Sociale Regione Emilia-Romagna, Bologna, Italy

2. Dipartimento di Sanità Pubblica, Area Igiene e Sanità Pubblica, Azienda USL, Bologna, Italy

3. Azienda Ospedaliero-Universitaria di Bologna Policlinico S.Orsola-Malpighi, Bologna, Italy

4. Infection Prevention and Control Global Unit, WHO Service Delivery and Safety, World Health Organization, Geneva, Switzerland

5. Ufficio 5 - Rapporti con l'Unione Europea, il Consiglio d'Europa, l'OCSE, l'OMS, e le altre agenzie ONU ed Organizzazioni internazionali, Direzione generale della comunicazione e dei rapporti europei e internazionali, Ministero della Salute, Rome, Italy

6. Infection Control Programme and WHO Collaborating Centre on Patient Safety, University of Geneva Hospitals and Faculty of Medicine, Geneva, Switzerland

Correspondence: Filomena Morsillo (fmorsillo@regione.emilia-romagna.it)

Moro ML, Morsillo F, Nascetti S, Parenti M, Allegranzi B, Pompa MG, Pittet D. Determinants of success and sustainability of the WHO multimodal hand hygiene promotion campaign, Italy, 2007-2008 and 2014. Euro Surveill. 2017;22(23):pii=30546. DOI: http://dx.doi.org/10.2807/1560-7917.ES.2017.22.23.30546

A national hand hygiene promotion campaign based on the World Health Organization (WHO) multimodal, Clean Care is Safer Care campaign was launched in Italy in 2007. One hundred seventy-five hospitals from 14 of 20 Italian regions participated. Data were collected using methods and tools provided by the WHO campaign, translated into Italian. Hand hygiene compliance, ward infrastructure, and healthcare workers' knowledge and perception of healthcare-associated infections and hand hygiene were evaluated before and after campaign implementation. Compliance data from the 65 hospitals returning complete data for all implementation tools were analysed using a multilevel approach. Overall, hand hygiene compliance increased in the 65 hospitals from $40 \%$ to $63 \%$ (absolute increase: $23 \%$, $95 \%$ confidence interval: $22-24 \%$ ). A wide variation in hand hygiene compliance among wards was observed; inter-ward variability significantly decreased after campaign implementation and the level of perception was the only item associated with this. Long-term sustainability in 48 of these 65 hospitals was assessed in 2014 using the WHO Hand Hygiene Self-Assessment Framework tool. Of the 48 hospitals, 44 scored in the advanced/intermediate categories of hand hygiene implementation progress. The median hand hygiene compliance achieved at the end of the 2007-2008 campaign appeared to be sustained in 2014 .

\section{Introduction}

In recent years, increasing attention has been given to hand hygiene as a leading measure to prevent the spread of antimicrobial resistance and to reduce healthcare-associated infections (HAls) [1]. Several studies offer convincing evidence that improved hand hygiene practices lead to a reduction of HAls and/or transmission or colonisation by multidrug-resistant organisms (MDROs) [2].

In October 2005, the World Health Organization (WHO) launched Clean Care is Safer Care, a global hand hygiene campaign [3]. Aimed to reduce HAls it focused on implementing new hand hygiene recommendations [4] through a multimodal hand hygiene promotion campaign [5]. At that time, the Italian Minister of Health signed a statement to show its commitment to reducing HAls [6]. Consequently, a national hand hygiene campaign based on the materials provided by WHO was launched in November 2006. The campaign was organised by the national coordinating centre for HAls (Agenzia Sanitaria e Sociale Regionale Emilia-Romagna) and funded by the National Centre for Disease Control (Centro Nazionale per la Prevenzione e il Controllo delle Malattie). The multimodal national campaign was conducted in 2007-2008 and not repeated in the following years.

This study reports the campaign's effect on hand hygiene compliance immediately after implementation, and identifies factors associated with the observed improvement at the individual level and at the ward level. It also reports on the level of hand hygiene compliance 7 years later. 
Compliance with hand hygiene at baseline and follow-up across professional categories, type of indication and ward, national campaign, Italy, 2007-2008

\begin{tabular}{|c|c|c|c|c|c|c|}
\hline & \multicolumn{2}{|c|}{ Baseline } & \multicolumn{2}{|c|}{ Follow-up } & \multirow[b]{2}{*}{$\begin{array}{l}\text { Absolute difference } \\
\text { in compliance } \\
(\%)\end{array}$} & \multirow[b]{2}{*}{$95 \% \mathrm{Cl}$} \\
\hline & $\begin{array}{l}\text { Opportunities } \\
\text { (n) }\end{array}$ & Compliance (\%) & Opportunities (n) & Compliance (\%) & & \\
\hline Overall & 18,045 & 40 & 17,577 & 63 & +23 & $22-24$ \\
\hline \multicolumn{7}{|l|}{ Professional category } \\
\hline Nurses & 11,732 & 42 & 11,506 & 67 & +25 & $24-26$ \\
\hline Medical doctors & 3,849 & 39 & 3,693 & 55 & +16 & $14-18$ \\
\hline Auxiliary & 1,960 & 33 & 2,114 & 61 & +28 & $25-31$ \\
\hline Other & 504 & 28 & 264 & 46 & +18 & $11-25$ \\
\hline \multicolumn{7}{|l|}{ Hand hygiene indication } \\
\hline Before patient contact & 5,538 & 33 & 5,494 & 59 & +26 & $24-28$ \\
\hline Before aseptic task & 2,109 & 45 & 2,008 & 64 & +19 & $16-22$ \\
\hline $\begin{array}{l}\text { After contact with patient } \\
\text { surroundings }\end{array}$ & 3,602 & 25 & 3,141 & 50 & +25 & $23-27$ \\
\hline After patient contact & 5,117 & 50 & 5,070 & 71 & +21 & $19-23$ \\
\hline $\begin{array}{l}\text { After body fluid exposure } \\
\text { risk }\end{array}$ & 1,679 & 55 & 1,864 & 75 & +19 & $16-22$ \\
\hline \multicolumn{7}{|l|}{ Type of ward } \\
\hline Surgical & 4,762 & 31 & 4,735 & 56 & +25 & $23-27$ \\
\hline Intensive care & 10,618 & 42 & 10,076 & 65 & +23 & $22-24$ \\
\hline Medical and other wards & 2,665 & 45 & 2,766 & 67 & +22 & $20-25$ \\
\hline \multicolumn{7}{|l|}{ Type of hospital } \\
\hline Private & 599 & 25 & 589 & 45 & +20 & $15-26$ \\
\hline Public & 15,511 & 40 & 15,190 & 63 & +23 & $22-24$ \\
\hline Research/teaching & 1,935 & 41 & 1,798 & 71 & +30 & $27-33$ \\
\hline
\end{tabular}

$\mathrm{Cl}$ : confidence interval.

\section{Methods}

\section{Implementing WHO's Clean Care is Safer Care campaign}

In November 2006, Italian public hospitals were invited by regional coordinators to implement the WHO's Clean Care is Safer Care hand hygiene promotion campaign. Hospitals were asked to have at least one or two wards with at least one hand washing basin for every 10 beds participate, with intensive care units (ICUs), surgical wards or onco-haematology/transplant wards being most preferred.

The Italian campaign was based entirely on the WHO's [3], and involved all WHO documents and tools [7] being translated into Italian and then made available on the Ministry of Health website [8]. The campaign tools were focused on the following five elements: (i) system change, including access to alcohol-based hand rub (ABHR); (ii) healthcare workers' (HCWs) training and education; (iii) monitoring and feedback on practices; (iv) visual reminders in the workplace; and (v) institutional patient-safety climate $[5,9]$.
Implementation of the campaign occurred from November 2006 onwards and in the following four stages: (i) preparedness (3 months on average); (ii) baseline evaluation (2.5 months on average); (iii) intervention ( 3 months on average); and (iv) follow-up evaluation (2.5 months on average) [5].

\section{Evaluating short-term impact of the campaign}

The follow-up evaluation (implementation stage 4 as per above) was carried out from March 2007 to October 2008. Only hospitals/wards with data available from both the baseline evaluation and follow-up evaluation phases were included in the analysis.

Participating hospitals were requested to send all data collected via four questionnaires, provided by the WHO campaign [5,7] and translated into Italian [8], for facility situation (at baseline only), ward infrastructure, hand hygiene knowledge (anonymous) and hand hygiene perception (anonymous), as well as observations about hand hygiene compliance to the Agenzia Sanitaria e Sociale Regionale Emilia-Romagna. Hand hygiene perception explored HCW's perceptions about their own hand hygiene compliance, the compliance of other HCWs, the impact of HAls, the importance of 
TABLE 2

Factors associated with hand hygiene compliance at baseline and follow-up, national campaign, Italy, 2007-2008

\begin{tabular}{|c|c|c|c|c|c|c|}
\hline & \multicolumn{3}{|c|}{ Baseline } & \multicolumn{3}{|c|}{ Follow-up } \\
\hline & OR & $95 \% \mathrm{Cl}$ & $\mathrm{p}$ value & OR & $95 \% \mathrm{Cl}$ & $p$ value \\
\hline \multicolumn{7}{|l|}{ Hand hygiene indication } \\
\hline After body fluid exposure risk & Ref. & NA & NA & Ref. & NA & NA \\
\hline After patient contact & 0.75 & $0.65-0.85$ & $<0.0001$ & 0.78 & $0.68-0.89$ & $<0.0001$ \\
\hline After contact with patient surroundings & 0.28 & $0.24-0.32$ & $<0.0001$ & 0.32 & $0.28-0.37$ & $<0.0001$ \\
\hline Before patient contact & 0.32 & $0.28-0.37$ & 0.004 & 0.45 & $0.39-0.52$ & $<0.0001$ \\
\hline Before aseptic task & 0.59 & $0.50-0.68$ & $<0.0001$ & 0.54 & $0.46-0.64$ & $<0.0001$ \\
\hline \multicolumn{7}{|l|}{ Professional category } \\
\hline Nurses & Ref. & NA & NA & Ref. & NA & NA \\
\hline Medical doctors & 0.74 & $0.68-0.81$ & $<0.0001$ & 0.54 & $0.49-0.59$ & $<0.0001$ \\
\hline Auxiliary & 0.69 & $0.61-0.79$ & $<0.0001$ & 0.81 & $0.72-0.92$ & $<0.0001$ \\
\hline Other professionals & 0.48 & $0.38-0.61$ & $<0.0001$ & 0.31 & $0.23-0.42$ & $<0.0001$ \\
\hline \multicolumn{7}{|l|}{ Type of hospital } \\
\hline Research/teaching & Ref. & NA & NA & Ref. & NA & NA \\
\hline Private & 1.39 & $0.26-2.86$ & 0.643 & 1.00 & $0.24-2.41$ & 0.995 \\
\hline Public & 2.00 & $0.50-3.56$ & 0.080 & 1.10 & $0.10-3.04$ & 0.801 \\
\hline Facility situation score greater than the median ${ }^{a}$ & 1.12 & $0.09-3.03$ & 0.645 & 1.35 & $0.13-3.49$ & 0.211 \\
\hline \multicolumn{7}{|l|}{ Type of ward } \\
\hline Medical and other wards & Ref. & NA & NA & Ref. & NA & NA \\
\hline Surgical ward & 0.48 & $0.35-0.85$ & 0.047 & 0.69 & $0.66-1.92$ & 0.296 \\
\hline ICU & 1.08 & $0.54-1.85$ & 0.818 & 0.91 & $0.78-3.13$ & 0.770 \\
\hline $\begin{array}{l}\text { Ward infrastructure for hand hygiene score greater than } \\
\text { the median }\end{array}$ & 2.05 & $1.50-7.06$ & 0.015 & 1.50 & $0.70-12.40$ & 0.093 \\
\hline Knowledge score greater than the median ${ }^{a}$ & 1.42 & $0.19-5.65$ & 0.144 & 1.28 & $0.24-6.76$ & 0.313 \\
\hline Perception score greater than the median ${ }^{a}$ & 0.88 & $0.07-1.35$ & 0.637 & 1.75 & $1.50-32.50$ & 0.022 \\
\hline \multicolumn{7}{|l|}{ Measures of hand hygiene compliance variability } \\
\hline Ward level variance $^{\mathrm{b}}$ & 0.92 & $0.69-1.37$ & NA & 0.85 & $0.63-1.27$ & NA \\
\hline Change in variance $^{c}$ & $-22 \%$ & NA & NA & $-30 \%$ & NA & NA \\
\hline Intra-class correlation ${ }^{d}$ & $22 \%$ & NA & NA & $20 \%$ & NA & NA \\
\hline
\end{tabular}

Cl: confidence interval; ICU: intensive care unit; OR: odds ratio.

a Dummy variable yes vs no.

b Standard Error (SE) in the empty model is $1.182(0.203)$ and $1.213(0.216)$, baseline and follow-up respectively.

c Proportional reduction change in variance (PVC).

${ }^{d}$ Intra-class correlation coefficient (ICC) in the empty model is $26 \%$ and $29 \%$, baseline and follow-up respectively.

hand hygiene as a preventive measure to reduce HAls and the effectiveness of the different elements of a multimodal strategy. A total score for each of the four questionnaire areas [5,7] was calculated as the ratio of the response score to the maximum expected score (i.e. sum of the all items in the questionnaire/(overall maximum expected score $x$ number of non-missing items)). Thus, each of the areas received scores ranging from 0 to 1.

Data on hand hygiene compliance was collected via a trained, unobtrusive observer who, during 20-minute sessions, openly observed staff and recorded the total number of hand hygiene opportunities and actions, either hand washing or hand rubbing $[5,7]$. An opportunity for hand hygiene was defined as the occurrence of any indication for hand hygiene according to the WHO
'My 5 Moments' approach $[7,9,10]$. Each ward had to record at least 200 opportunities; otherwise they were considered to have incomplete data and were excluded from the analysis [11].

\section{Determining long-term sustainability of the 2007-2008 campaign in 2014}

The long-term sustainability of hand hygiene behaviour change was assessed 7 years after the conclusion of the national campaign. In 2014, the 65 hospitals included in the follow-up evaluation of the 2007-2008 campaign were invited to complete the Hand Hygiene Self-Assessment Framework (HHSAF). This tool is part of the WHO Clean Care is Safer Care kit $[12,13]$, but was not a part of the tools used in the baseline and followup evaluations. The questionnaire comprises 27 items grouped into five sections reflecting the five elements 


\section{TABLE 3}

Survey results of hospitals participating in the 2007-2008 national campaign according to 2014 hand hygiene implementation level, Italy, 2014 ( $\mathrm{n}=48$ hospitals)

\begin{tabular}{|c|c|c|c|c|}
\hline \multirow[b]{3}{*}{ 2007-2008 campaign } & \multicolumn{4}{|c|}{ Implementation level in 2014} \\
\hline & \multicolumn{2}{|c|}{$\begin{array}{l}\text { Advanced } \\
(\mathrm{n}=12)\end{array}$} & \multicolumn{2}{|c|}{$\begin{array}{l}\text { Intermediate/basic } \\
\qquad(\mathrm{n}=36)\end{array}$} \\
\hline & Median & Interquartile range & Median & Interquartile range \\
\hline \multicolumn{5}{|l|}{ Hand hygiene compliance (observed/expected) } \\
\hline at baseline & 0.52 & $0.22^{\mathrm{a}}$ & 0.37 & $0.28^{\mathrm{a}}$ \\
\hline at follow-up & 0.74 & 0.21 & 0.63 & 0.28 \\
\hline \multicolumn{5}{|c|}{ Ward infrastructure for hand hygiene score (questionnaire) } \\
\hline at baseline & 0.67 & $0.25^{\mathrm{a}}$ & 0.33 & $0.50^{\mathrm{a}}$ \\
\hline at follow-up & 0.84 & 0 & 0.83 & 0.17 \\
\hline \multicolumn{5}{|l|}{ Knowledge score (questionnaire) } \\
\hline at baseline & 0.53 & 0.07 & 0.53 & 0.07 \\
\hline at follow-up & 0.75 & 0.24 & 0.74 & 0.26 \\
\hline \multicolumn{5}{|l|}{ Perception score (questionnaire) } \\
\hline at baseline & 0.77 & $0.11^{\mathrm{a}}$ & 0.69 & $0.06^{a}$ \\
\hline at follow-up & 0.84 & 0.08 & 0.77 & 0.07 \\
\hline 2014 survey & $\begin{array}{l}\text { Median score/max } \\
\text { achievable score }\end{array}$ & Interquartile range & $\begin{array}{l}\text { Median score/max } \\
\text { achievable score }\end{array}$ & Interquartile range \\
\hline HHSAF & $450 / 500$ & 60 & $322.5 / 500$ & 77.5 \\
\hline \multicolumn{5}{|l|}{ Components scores of HHSAF } \\
\hline System change & $100 / 100$ & 0 & $90 / 100$ & 20 \\
\hline Training and education & $100 / 100$ & 10 & $65 / 100$ & 10 \\
\hline Evaluation and feedback & $80 / 100$ & 10 & $55 / 100$ & 35 \\
\hline Reminders in the workplace & $90 / 100$ & 20 & $65 / 100$ & 12 \\
\hline Institutional safety climate for hand hygiene & $90 / 100$ & 30 & $40 / 100$ & 20 \\
\hline \multicolumn{5}{|l|}{ Selected items of HHSAF } \\
\hline Training and education ${ }^{b}$ & $40 / 40$ & 0 & $20 / 40$ & 20 \\
\hline $\begin{array}{l}\text { Evaluation and feedback: hand hygiene } \\
\text { compliance }^{c}\end{array}$ & $25 / 30$ & 6 & $15 / 30$ & 15 \\
\hline Institutional safety climate for hand hygiene ${ }^{d}$ & $20 / 20$ & 0 & $15 / 20$ & 11.2 \\
\hline Institutional safety climate for hand hygiene $e^{e}$ & $10 / 10$ & 10 & $0 / 10$ & 0 \\
\hline Institutional safety climate for hand hygiene $e^{f}$ & $5 / 5$ & o & $0 / 10$ & 5 \\
\hline Institutional safety climate for hand hygiene ${ }^{g}$ & $10 / 10$ & 2.5 & $0 / 10$ & 0 \\
\hline
\end{tabular}

HHSAF: Hand Hygiene Self-Assessment Framework; IQR: interquartile range.

advanced vs intermediate/basic: $p$ value $<0.05$.

${ }^{b}$ Item 2.1a, 2.1b: Mandatory training for all professional categories at commencement of employment, then ongoing regular training (at least annually).

c Overall hand hygiene compliance rate according to the WHO Hand Hygiene Observation tool (or similar technique): 25 points corresponds to compliance equal to $71-80 \% ; 15$ points corresponds to compliance of $51-60 \%$.

${ }^{d}$ Visible commitment to support hand hygiene improvement by the Chief Executive Officer, the Medical Director, the Director of Nursing.

${ }^{\text {e }}$ A clear plan for the promotion of hand hygiene throughout the entire facility for the annual global campaign on 5 May, Save Lives: Clean Your Hands.

${ }^{f}$ Patients informed about the importance of hand hygiene (e.g. via a leaflet).

${ }^{\mathrm{g}} \mathrm{A}$ formalised programme of patient engagement.

of the multimodal campaign (e.g. system change; training and education; evaluation and feedback; reminders in the workplace; and institutional safety climate). Each component section is scored out of 100 points (total maximum score: 500), and based on this, responding healthcare facilities were classified as inadequate ( $\leq$ 125 points), basic (126-250), intermediate (251-375) or advanced (> 375) [12,13]. Notably, the HHSAF asked hospitals to report on the level of hand hygiene compliance obtained through direct observation.
Statistical analysis

The following statistical methods were used to analyse the impact of the campaign.

Pearson's chi-squared test and McNemar test were used where appropriate to investigate the difference between proportions.

For facility situation, ward infrastructure, hand hygiene knowledge and hand hygiene perception, the 
Cronbach's alpha coefficient was used to estimate the reliability of sets of questionnaire items before calculating the scores (alpha values higher than $70 \%$ were considered acceptable) and the internal consistency between different items [14]. A non-parametric $\mathrm{K}$-sample test on the equality of medians was used to test the differences among scores.

Compliance data were analysed using a multilevel approach $[15,16]$ with hand hygiene opportunities as first level and ward characteristics as second level. The following first level covariates were used: professional category, hand hygiene indication and study phase (baseline and follow-up). Second level covariates were ward specialty, type of facility, the score related to the facility situation before the intervention, the ward structure score for hand hygiene, and HCWs' knowledge and perception score in each ward before and after the campaign implementation. The number of observed opportunities per hour of observation $[17,18]$ and the average hand hygiene compliance at baseline were used in the model evaluating the impact of the campaign.

A logistic multilevel regression model at mixed effects with binomial distribution and logit link was used to explore the effect of hand hygiene indications and professional categories taking different ward characteristics into account [19]. Two random intercept models were fitted, separately for baseline and follow-up phases, to investigate whether there was significant clustering within wards in relation to hand hygiene compliance, to which extent the variance among wards was explained by ward opportunities mix, and whether specific ward characteristics were associated with compliance variance among wards.

The intra-class correlation (ICC) was used to measure the proportion of the overall variance in hand hygiene compliance explained by the clustering variable. Compliance at baseline in each ward was used to correct the compliance variance estimate. The proportional change in variance (PVC) was used to measure the reduction of variance compared with the empty model or to the previous model. A bivariate analysis was used, overall and also separately for the three types of ward (surgical, intensive care, and medical/ other wards) to investigate whether the relative change in hand hygiene compliance was statistically associated with the relative change in ward infrastructure, hand hygiene knowledge and hand hygiene perception questionnaire scores at ward level at follow-up. The relative change in compliance was defined as the absolute difference between two overall measurements (at baseline and follow-up) compared with the baseline measurement in each ward. We applied a linear regression model with bootstrap estimation.

Statistical analyses were performed using STATA/IC 11.1.

\section{Results}

Fourteen of 20 regions in Italy agreed to actively participate in the campaign, leading to a total involvement of 175 hospitals comprised of 285 wards. Of the 175 hospitals, 65 returned complete data (37.1\%). The variation in participation across regions was not explained by any particular reason. Of the 285 wards, 200 were excluded; 190 (95\%) because they were unable to perform all of the requested hand hygiene observations and $10(5 \%)$ because not all the questionnaires were sent back. This left 85 wards (29.8\%) remaining for the analysis, which were included. The 65 hospitals included in the analysis were similar to the 110 excluded hospitals in terms of public ownership ( $83 \%$ vs $80 \%$ ) and infection control score before the campaign $(40 \%$ vs $39 \%$ ). The 85 wards included in the analysis were more frequently intensive care units (ICUs) compared with the 172 excluded wards ( $56 \%$ vs $45 \%$, chi-square 3.1, $\mathrm{p}$ value $=0.038$ ).

In terms of observed compliance, a total of 18,045 opportunities for hand hygiene were recorded at baseline and 17,577 at follow-up; the number of observation sessions was 1,643 at baseline and 1,403 at follow-up with a median duration of 20 minutes for both baseline and follow-up (IQR: 15 and 10, respectively). The median number of opportunities observed per hour was 20 for baseline and 24 for follow-up (IQR: 24 and 21 , respectively). The distribution of observed opportunities was similar during both phases (Table 1 ).

Of the 65 hospitals included in the 2007-2008 followup evaluation, 48 participated in the $2014 \mathrm{HHSAF}$ survey to assess the level of implementation of hand hygiene over time: 40 of 56 public hospitals, six of seven teaching hospitals, and two of two private hospitals.

Impact of campaign, 2007-2008

At baseline, the facility situation median score (measured at baseline only) was high (0.77) and showed small inter-hospital variation (IQR: 0.143), but the ward infrastructure median score was low (0.50) with considerable inter-ward variation (IQR: 0.50). At follow-up, scores arising from the three baseline/follow-up questionnaire areas increased significantly: the ward infrastructure median score increased to from 0.50 to 0.83 ( $p$ value $<0.0001$ ), the hand hygiene knowledge median score increased from 0.53 to 0.68 ( $p$ value $<0.0001$ ) and the hand hygiene perception median score increased from to 0.69 to 0.77 ( $p$ value<0.0001).

Overall, hand hygiene compliance increased from $40 \%$ to $63 \%$ (absolute increase: $23 \%$, 95\% confidence interval $(\mathrm{Cl}): 22-24 \%)$. Compliance significantly increased across all professional categories, types of hand hygiene indications, types of wards and types of hospitals, with the extent of compliance increase being greatest for those areas that showed low compliance before intervention (Table 1 ). 
At baseline, hand hygiene compliance was significantly associated with the type of professional category, the type of hand hygiene indication, the type of ward speciality, and the ward structure for hand hygiene score. Compliance was highest for the professional category of nurses ( $p<0.0001$ ), for the indication of 'after body fluid exposure risk' ( $p$ value $<0.0001$ ), and for medical wards ( $p$ value $<0.05$ ) (Table 2). At follow-up, compliance was significantly associated with the type of professional category, the type of hand hygiene indication and the perception score (Table 2).

Notably, a wide variation in hand hygiene compliance among wards was observed at baseline and followup. The variance was significant in the empty models both before and after the intervention, and both the before and after ICCS were high (Table 2). At baseline, inter-ward variability of hand hygiene compliance after adjusting for major confounders was seen, with ICUs and medical/other wards having significantly higher compliance than surgical wards ( $p$ value $=0.047$ ). This inter-ward variability decreased after campaign implementation, with perception being the only factor significantly associated with this ( $p$ value $=0.022$ ) In ICUs and surgical wards, perception was strongly associated with increased hand hygiene compliance at follow-up. Correlating the relative change in overall hand hygiene compliance to the changes in the hand hygiene perception, hand hygiene knowledge and ward infrastructure scores showed that only hand hygiene perception scores were significantly associated with the change (beta-coefficient: 0.343 , $p$ value $<0.0001$ ).

\section{Long-term sustainability of campaign, 2014}

Of the 48 hospitals that completed the HHSAF, the median HHSAF score was 345 (Interquartile range (IQR): 83.7) and 44 were in the intermediate or advanced levels of hand hygiene implementation progress. Overall, the highest component score was for system change (median 100.0, IQR: 20), while the lowest was for institutional safety climate (median 50, IQR: 35). All 12 hospitals that reached the advanced level completed the leadership section; their median leadership score was 14.0 (IQR: 4).

Table 3 describes the 48 hospitals using data collected during the baseline and follow-up evaluations of the 2007-2008 campaign, and data collected during the 2014 HHSAF survey.

Facilities classified as advanced via the HHSAF questionnaire in 2014 were already better performers when the 2007-2008 campaign was initiated: at baseline in 2007-2008, the median scores for hand hygiene compliance ( 0.52 vs 0.37 , chi-squared test $4.28, p$ value $=0.0384$ ), ward infrastructure (0.67 vs 0.33 , chi-squared test $4.17, \mathrm{p}$ value $=0.0411)$, and hand hygiene perception ( 0.77 vs 0.69 , chi-squared test 7.47, $p$-value $=0.0063$ ) were significantly higher for facilities classified as advanced compared with those classified as intermediate or basic in 2014. Observed changes between the baseline and follow-up evaluations were comparable between advanced and intermediate/basic facilities with the exception of ward infrastructure for hand hygiene: this improved more among facilities classified as intermediate or basic in 2014 (0.50 median absolute change, IQR: 0.50 vs 0.17 median absolute change, IQR: 0.17 , chi-squared test 10.94 , $p$ value $=0.0009$ ). In 2014, the median hand hygiene compliance achieved at the end of the 20072008 campaign appeared to be sustained. For the 12 hospitals classified as advanced in 2014, the median reported hand hygiene compliance score was 25 points (corresponding to $71-80 \%$ compliance) in 2014 while the median observed hand hygiene compliance at follow-up was $74 \%$ in 2007-2008. For the 36 intermediate/basic hospitals, the median 2014-reported compliance was 15 points (corresponding to $51-60 \%$ compliance) while the median 2007-2008 observed compliance at follow-up was $63 \%$ (Table 3).

\section{Discussion}

Implementation of a multimodal promotion campaign in 65 hospitals at the national level in Italy led to significant hand hygiene compliance improvement across all types of wards and professional categories.

The inclusion of several hospitals and wards across Italy allowed us to explore factors explaining the variability in hand hygiene compliance among different wards, both before and after campaign implementation. Consistent with previous reports [4], compliance varied across professional categories and types of hand hygiene indications. Nurses started with and achieved the highest level of hand hygiene compliance, consistent with a systematic review of 96 studies that showed median compliance rates $16 \%$ lower among physicians compared with nurses [20]. Compliance was highest with the indication 'after contact with body fluids' both at baseline and follow-up. This was consistent with several studies that have demonstrated that hand hygiene action is more frequently performed after contact with body fluids or after patient contact than before, possibly suggestive of self-protection against harmful organisms $[4,21]$.

Compliance increase was indeed accompanied by a parallel improvement in all factors shown to influence hand hygiene behaviour: availability of hand hygiene products within the ward, knowledge of hand hygiene principles, perception of the importance of hand hygiene and of multimodal actions to improve hand hygiene. This is consistent with that reported in other campaigns [9].

The results of the study show that perception characterises the variability in hand hygiene compliance across wards following intervention, and confirms that improving perception of HAls and hand hygiene improve hand hygiene behaviour. 
Others have also found that hand hygiene is influenced by the perceived behaviour of other healthcare professionals [22] and that education methods to enhance perception are requisites for success [18]. In our campaign, several innovative methods were used to promote knowledge and perceptions, such as videos of real-life situations, experiential learning and participatory sessions. Given that others have found that using innovative methods is a key factor for success [21], it is anticipated that the innovative methods used to promote improved knowledge and perception in this study may have been effective at addressing existing behavioural barriers to hand hygiene, especially in settings where compliance was low, such as surgical wards.

Understanding which factors may be important to reducing the variability across wards is of paramount importance to achieving a uniform high level of hand hygiene compliance. Saint et al. found a significant variability of hand hygiene compliance across five wards in Tuscany: the highest performing ward was characterised by the commitment of its physician leaders to hand hygiene improvement and the early adoption of ABHR [23]. Our results confirm both the feasibility and the effectiveness of a large scale implementation of a multimodal hand hygiene promotion campaign, thereby supporting the systematic review and network meta-analysis recently published by Luangasanatip et al [24].

Few studies have reported on long-term hand hygiene compliance [24], especially after a one-off national campaign. The long-term results of the HHSAF survey conducted in 2014 are very encouraging: 7 years after the end of the campaign and without any campaigning activity at the national level thereafter, hospitals that implemented the campaign were still actively promoting hand hygiene. Of the 48 hospitals completing the HHSAF survey, 44 were classified as intermediate or advanced in terms of hand hygiene implementation progress. This compares with $94 \%(122 / 129)$ in the most recent similar survey conducted in the United States using the same tool [13].

All 48 hospitals were still implementing the core components of the WHO campaign even though the campaign itself was not repeated: training scored 40/40 in advanced hospitals vs $20 / 40$ in the other hospitals; hand hygiene direct observation was claimed to still be in place and $71-80 \%$ compliance was reported by advanced hospitals vs $51-60 \%$ in the others; visible commitment to hand hygiene was assured by top managers scoring $20 / 20$ in advanced hospitals vs $15 / 20$ in the others. Institutions classified as advanced in 2014 were already more prone to hand hygiene promotion at baseline in 2007-2008.

Our study has limitations. First, while we explored the effect of both individual variables, such as professional category and hand hygiene indications, as well as hospital and ward characteristics on compliance, we could not consider additional factors such as the potential positive role of opinion leaders or early adopters. Such investigations are extremely difficult to conduct on a large scale and should be considered as next steps. Second, since hospital participation was voluntary, those participating were possibly more inclined to improve than others. The median facility situation score showing 0.77 at baseline was indeed high with small inter-hospital variability, while Italian national data show significant variation in the development of infection control organisations and initiatives by region and type of hospital [25]. Moreover, we only received full 2007-2008 follow-up data from a subsample of the 175 participating hospitals $(37 \%(n=65))$ mainly due to the unavailability of all the requested data (knowledge, perception, and ward questionnaires and/or hand hygiene observations). Based on the information available, the 65 participating hospitals were similar to the excluded ones in terms of public ownership and infection control activities in place before the campaign. One difference was that the participating hospitals have more ICUs, but the possible effect on the results was minimal. Third, the so called 'Hawthorne effect may have occurred [26]; however, its overall impact is difficult to quantify when the direct observation of practices is conducted and it cannot explain the observed uniform improvement shown across all sites, wards and professional categories in 2007-2008 or the observed sustainability 7 years later. Fourth, this study is limited by the absence of data on patient outcomes, which it was not designed to monitor. Given the high number of enrolled wards not performing HAl surveillance, implementing infection surveillance to evaluate the impact of the campaign on patient outcomes for the duration of the study or using available surveillance data from a proportion of wards only was considered unfeasible and potentially inaccurate. However, a large number of other studies have explored the link between hand hygiene and infection rates [1] and investigators continue to add positive evidence [27-30].

In conclusion, the national campaign using a translated version of the WHO Clean Care is Safer Care materials was effective in improving hand hygiene compliance across 65 hospitals in Italy in 2007-2008: increased perception of HAls and hand hygiene was an important driver for improvement. The campaign, which was not repeated in following years, seems to have contributed to a good level of hand hygiene 7 years later in 48 of these hospitals.

\section{Acknowledgements}

We would like to thank all regional and hospital coordinators, as well as all healthcare workers involved in the national campaign. The 'Clean Care is Safer Care' inter-regional network was composed of: Rosalba Barone (Regione Calabria); Renato Pizzuti (Regione Campania); Maria Luisa Moro, Simona Nascetti, Mita Parenti (Regione Emilia-Romagna); Margherita Vizio, Maura Nannini (Regione Liguria); Marcello D’Errico, Emilia Prospero, Enrica Carducci (Regione Marche); Francesco Bernieri, Anna Pavan (Regione Lombardia); 
Carla Zotti, Giacomo Conterno (Regione Piemonte); Peter Josef Santa (Provincia autonoma di Bolzano); Luca Fabbri, Giannina Piccini (Provincia autonoma di Trento); Rosa Prato (Regione Puglia); Paolo Cantaro, Lorenzo Maniaci (Regione Sicilia); Anna Poli, Gaetano Privitera (Regione Toscana); Alessandro Montedori, Maurizio Fiorio (Regione Umbria); Marisa Mastaglia (Regione Valle d'Aosta); Ugo Fedeli, Paolo Spolaore (Regione Veneto). We also want to thank the following hospital coordinators for having contributed to the HHSAF in 2014: Antonioli Paola (Azienda Ospedaliera Universitaria di Ferrara); Argentero Pier Angelo (Azienda Sanitaria Locale $\mathrm{TO}_{3}$ - Distretto di Collegno); Attanasio Giovanni (Azienda Sanitaria Locale T01 - Distretto Città di Torino); Avanzato Marilena, Bianco Paola (Azienda Sanitaria Locale $\mathrm{TO}_{2}$. Distretto Città di Torino); Barbaro Silvana, Zozzoli Susanna, Finotto Giuseppe (Azienda Ospedaliera Molinette San Giovanni Battista di Torino); Bedosti Catia (Azienda Usl di Imola); Bellocchi Patrizia (Azienda Ospedaliera Universitaria 'Policlinico Vittorio Emanuele'); Berto Paola (Azienda Sanitaria Locale $\mathrm{TO}_{2}$ - Distretto Città di Torino); Bianchi Emanuela (Azienda Ospedaliera Ospedale di Circolo di Melegnano); Bona Maria Carolina, Macchi Antonella (Azienda Ospedaliera della Provincia di Pavia); Brunelli Davide, Zanella Maria Angela (Ospedale Sacro Cuore Don Calabria - Negrar di Verona); Brusaferro Marco, Marchetto Raffaella (Azienda Ulss 18 di Rovigo); Castellana Marilena, Sisti Marzio, Cesena Rossana, Firetti Anna (Azienda Usl Piacenza); Corrado Vallino, Boux Michela, Musca Rosa (Azienda Sanitaria Locale TO4 - Distretto di Chivasso); Corrado Vallino, Naretto Silvia (Azienda Sanitaria Locale TO4 - Distretto di Ivrea); D’Aloia Francesco (Azienda Sanitaria Locale BI - Biella); Dellalibera Ornella (Azienda Sanitaria Locale AL - Alessandria); Fabbri Luca, Piccini Giannina (Azienda Provinciale Servizi Sanitari di Trento); Farruggia Patrizia (Azienda Usl di Bologna); Fenu Piero, Bagnato Silvia (Azienda Ospedaliera Ordine Mauriziano di Torino); Grossi Paolo (Azienda Ospedaliera Ospedale di Circolo e Fondazione Macchi - Varese); Guareschi Giuliano (Azienda Sanitaria Ospedaliera Regina Margherita - S. Anna - Torino); Lania Donatella (Azienda Ospedaliera Mellino Mellini - Chiari); Marchionni Emilio, Borrini Bianca, Nulletti Tiziana (Azienda Usl Parma); Marinelli Lucia (Azienda Sanitaria Unica Regionale - Zona territoriale 9 di Macerata); Mastaglia Marisa (Azienda USL Valle d’Aosta); Mustara Domenico, Bisello Francesco, Carraro Mara (Azienda Ulss 15 Alta Padovana - Presidio Ospedaliero Camposampiero); Negri Rita (Azienda Ospedaliera Maggiore della Carità di Novara); Ossola Orietta, Pesce Roberta (Azienda Sanitaria Locale VCO - Distretto di Verbania); Parovina Giuseppe, Degiovanni Claudia (Azienda Sanitaria Locale AL Distretto di Casale Monferrato); Pastorelli Emanuela, Scipione Gatti, Franchino Manuela (Azienda Sanitaria Locale VC Distretto di Vercelli); Pellegrino Paolo, Ocelli Paola (Azienda Ospedaliera S. Croce e Carle di Cuneo); Poli Anna (Azienda Usl $10 \mathrm{di}$ Firenze); Pozzetti Cinzia (Azienda Usl di Ravenna); Raglio Annibale (Azienda Ospedaliera Ospedali Riuniti di Bergamo); Rebora Monica, Liggera Luisella (Azienda Sanitaria Locale CN1 Distretto di Savigliano); Rigo Alberto (Azienda Ulss 21 . Legnago); Russo Roberto, Rigobello Vilma (Presidio Sanitario Ospedale Cottolengo di Torino); Sacco Rosa Anna (IRCCS G. Gaslini di Genova); Salvatico Maurizio (Azienda Sanitaria Locale CN1- Mondovi); Tura Grazia Antonella (Azienda Usl di Rimini); Venturino Valentina (Azienda Sanitaria Locale CN2 - Alba).

Financial support provided by Centro per il Controllo e la Prevenzione delle Malattie (CCM), Health Ministry, Rome, Italy.

\section{Conflict of interest}

None declared.
Authors' contributions

B Allegranzi, S Nascetti, MG Pompa, D Pittet and ML Moro contributed to the design of study. S Nascetti, M Parenti and $\mathrm{F}$ Morsillo provided the collection and assembly of data. F Morsillo performed the data analysis. ML Moro and F Morsillo wrote the manuscript. B Allegranzi, D Pittet and ML Moro contributed with critical revision and reviewed the manuscript.

\section{References}

1. Allegranzi B, Pittet D. Role of hand hygiene in healthcareassociated infection prevention.J Hosp Infect. 2009;73(4):30515. DOI: 10.1016/j.jhin.2009.04.019 PMID: 19720430

2. World Health Organization (WHO). Evidence of hand hygiene to reduce transmission and infections by multi-drug resistant organisms in health-care settings. Geneva: WHO. [Accessed 21 May 2017]. Available from: http://www.who.int/gpsc/5may/ MDRO literature-review.pdf

3. Pittet D, Donaldson L. Clean Care is Safer Care: the first global challenge of the WHO World Alliance for Patient Safety. Infect Control Hosp Epidemiol. 2005;26(11):891-4. DOI: 10.1086/502513 PMID: 16320985

4. World Health Organization (WHO). WHO Guidelines on Hand Hygiene in Health Care: a Summary. First Global Patient Safety Challenge. Clean Care is Safer Care. Geneva: WHO; 2009.Available from: http://apps.who.int/iris/ bitstream/10665/70126/1/WHO_IER_PSP_2009.07_eng.pdf

5. World Health Organization (WHO). Guide to Implementation: A Guide to the Implementation of the WHO Multimodal Hand Hygiene Improvement Strategy. Geneva: WHO; 2007, revised in 2009. Available from: http://www.who.int/ infection-prevention/publications/hh_implementation-guide/ en/

6. World Health Organization (WHO). Clean Care is Safer Care: European countries statements. Geneva: WHO. [Accessed 30 May 2017]. Available from: http://www.who.int/gpsc/ statements/countries/EN_PSP_GSPC1-EURO_Country/en/

7. World Health Organization (WHO). Clean Care is Safer Care: Tools and Resources. Geneva: WHO. [Accessed 10 February 2015]. Available at: http://www.who.int/gpsc/5may/tools/en

8. World Health Organization (WHO). Campagna 'Cure pulite sono cure più sicure'. ['Clean Care is Safer Care' Campaign]. [Accessed 22 March 2017]. Italian. Available from: http://assr. regione.emilia-romagna.it/it/ricerca-innovazione/prevenzioneantibioticoresistenza-infezioni/sorveglianza-controllo/ controllo-rischio-infettivo/igiene-mani/cure-pulite-strumenti/ intro

9. Allegranzi B, Gayet-Ageron A, Damani N, Bengaly L, McLaws $M L$, Moro ML, et al. Global implementation of WHO's multimodal strategy for improvement of hand hygiene: a quasiexperimental study. Lancet Infect Dis. 2013;13(10):843-51. DOI: 10.1016/S1473-3099(13)70163-4 PMID: 23972825

10. Sax H, Allegranzi B, Uçkay I, Larson E, Boyce J, Pittet D. 'My five moments for hand hygiene': a user-centred design approach to understand, train, monitor and report hand hygiene.J Hosp Infect. 2007;67(1):9-21. DOI: 10.1016/j. jhin.2007.06.004 PMID: 17719685

11. Sax H, Allegranzi B, Chraïti MN, Boyce J, Larson E, Pittet D. The World Health Organization hand hygiene observation method. Am J Infect Control. 2009;37(10):827-34. DOI: 10.1016/j. ajic.2009.07.003 PMID: 20004812

12. World Health Organization (WHO). Hand Hygiene SelfAssessment Framework 2010. Geneva: WHO. [Accessed 22 March 2017]. Available from:http://www.who.int/gpsc/ country_work/hhsa_framework_October_2010.pdf?ua=1

13. Allegranzi B, Conway L, Larson E, Pittet D. Status of the implementation of the World Health Organization multimodal hand hygiene strategy in United States of America health care facilities.Am J Infect Control. 2014;42(3):224-30. DOI: 10.1016/j.ajic.2013.11.015 PMID: 24581011

14. Goldstein H. Multilevel Statistical Models. 2nd ed. London: Edward Arnold, 1995: 116-120.

15. Hox J. Multilevel Analysis: Techniques and Applications. 2nd ed. East Sussex: Routledge, 2010: 103-122.

16. Rabe-Hesketh S, Skrondal A. Multilevel and Longitudinal Modeling Using Stata. 2nd ed. Texas: Stata Press, 2008: 247252; 444-453.

17. Pittet D, Hugonnet S, Harbarth S, Mourouga P, Sauvan V, Touveneau S, et al. Effectiveness of a hospital-wide programme to improve compliance with hand hygiene. Lancet. 
2000;356(9238):1307-12. DOI: 10.1016/S0140-6736(00)02814-2 PMID: 11073019

18. Pittet D, Simon A, Hugonnet S, Pessoa-Silva CL, Sauvan V, Perneger TV. Hand hygiene among physicians: performance, beliefs, and perceptions. Ann Intern Med. 2004;141(1):1-8. DOI: 10.7326/0003-4819-141-1-200407060-00008 PMID: 15238364

19. Littell RC, Milliken GA, Stroup WW, Wolfinger RD. SAS System for Mixed Models. Cary, North Carolina: SAS Institute Inc., 1996: 253-266

20. Erasmus V, Daha TJ, Brug H, Richardus JH, Behrendt MD, Vos MC, et al. Systematic review of studies on compliance with hand hygiene guidelines in hospital care. Infect Control Hosp Epidemiol. 2010;31(3):283-94. DOI: 10.1086/650451 PMID: 20088678

21. Mathai E, Allegranzi B, Seto WH, Chraïti MN, Sax H, Larson E, et al. Educating healthcare workers to optimal hand hygiene practices: addressing the need. Infection. 2010;38(5):349-56 DOI: 10.1007/S15010-010-0047-7 PMID: 20857314

22. Erasmus V, Brouwer W, van Beeck EF, Oenema A, Daha TJ, Richardus $\mathrm{JH}$, et al. A qualitative exploration of reasons for poor hand hygiene among hospital workers: lack of positive role models and of convincing evidence that hand hygiene prevents cross-infection. Infect Control Hosp Epidemiol. 2009;30(5):415-9. DOI: 10.1086/596773 PMID: 19344264

23. Saint S, Bartoloni A, Virgili G, Mannelli F, Fumagalli S, di Martino $P$, et al. Marked variability in adherence to hand hygiene: a 5-unit observational study in Tuscany. Am J Infect Control. 2009;37(4):306-10. DOI: 10.1016/j.ajic.2008.08.004 PMID: 19135761

24. Luangasanatip N, Hongsuwan M, Limmathurotsakul D, Lubell Y, Lee AS, Harbarth S, et al. Comparative efficacy of interventions to promote hand hygiene in hospital: systematic review and network meta-analysis. BMJ. 2015;351:h3728. DOI: 10.1136/bmj.h3728 PMID: 26220070

25. Moro ML, Marchi M, Buttazzi R, Nascetti S, INF-OSS Project Group. Progress in infection prevention and control in Italy: a nationwide survey.J Hosp Infect. 2011;77(1):52-7. DOI: 10.1016/j. jhin.2010.08.009 PMID: 21131101

26. Whitby M, McLaws ML. Methodological difficulties in hand hygiene research.J Hosp Infect. 2007;67(2):194-5. DOI: 10.1016/j.jhin.2007.08.002 PMID: 17884247

27. Barnett AG, Page K, Campbell M, Brain D, Martin E, Rashleigh-Rolls R, et al. Changes in healthcare-associated Staphylococcus aureus bloodstream infections after the introduction of a national hand hygiene initiative. Infect Control Hosp Epidemiol. 2014;35(8):1029-36. DOI: 10.1086/677160 PMID: 25026620

28. Stone SP, Fuller C, Savage J, Cookson B, Hayward A, Cooper B, et al. Evaluation of the national Cleanyourhands campaign to reduce Staphylococcus aureus bacteraemia and Clostridium difficile infection in hospitals in England and Wales by improved hand hygiene: four year, prospective, ecological, interrupted time series study. BM). 2012;344(3 May 2012):e3005.PMID: 22556101

29. Ho ML, Seto WH, Wong LC, Wong TY. Effectiveness of multifaceted hand hygiene interventions in long-term care facilities in Hong Kong: a cluster-randomized controlled trial.Infect Control Hosp Epidemiol. 2012;33(8):761-7. DOI: 10.1086/666740 PMID: 22759542

30. Allegranzi B, Harbarth S, Pittet D. Effect of Hand Hygiene on Infection Rates. In: Pittet D, Boyce JM, Allegranzi B, editors. Hand Hygiene: A Handbook for Medical Professionals. Chichester: John Wiley and Sons, 2017.

\section{License and copyright}

This is an open-access article distributed under the terms of the Creative Commons Attribution (CC BY 4.0) Licence. You may share and adapt the material, but must give appropriate credit to the source, provide a link to the licence, and indicate if changes were made.

This article is copyright of the authors, 2017. 